\title{
Formulation and evaluation of mixed polymeric micelles of quercetin for treatment of breast, ovarian, and multidrug resistant cancers
}

This article was published in the following Dove Press journal: International Journal of Nanomedicine

\begin{abstract}
Arjun Patra, 1,2,* Swaha Satpathy, ${ }^{1,2, *}$ Anitha K Shenoy,' Jason A Bush, ${ }^{3}$ Mohsin Kazi, ${ }^{4}$ Muhammad Delwar Hussain ${ }^{1, *}$

'College of Pharmacy, Department of Pharmaceutical and Biomedical Sciences, California Health Sciences University, Clovis, CA, USA; 'Institute of Pharmacy, Guru Ghasidas Vishwavidyalaya, Bilaspur (C.G.), India; ${ }^{3}$ Department of Biology, California State University, Fresno, CA, USA; ${ }^{4}$ Kayyali Chair for Pharmaceutical Industries, College of Pharmacy, King Saud University, Riyadh, Saudi Arabia

*These authors contributed equally to this work
\end{abstract}

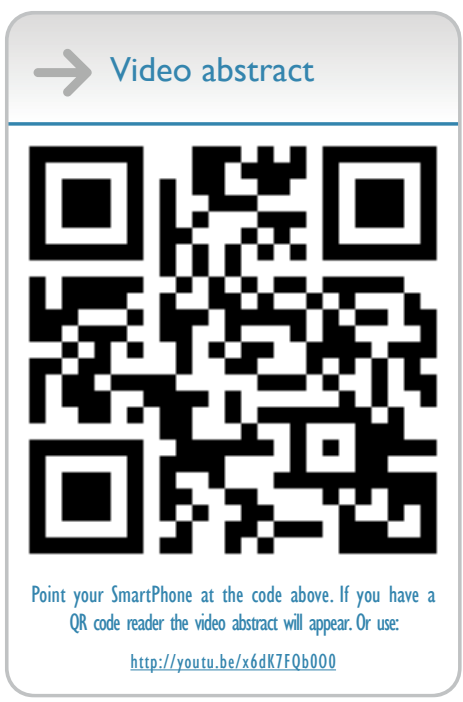

Correspondence: Muhammad Delwar Hussain College of Pharmacy, Department of Pharmaceutical and Biomedical Sciences, California Health Sciences University, I 20 N Clovis Ave, Clovis, CA 93612, USA Email dhussain@chsu.org
Background: Quercetin (QCT), a naturally occurring flavonoid has a wide array of pharmacological properties such as anticancer, antioxidant and anti-inflammatory activities. QCT has low solubility in water and poor bioavailability, which limited its use as a therapeutic molecule. Polymeric micelles (PMs) is a novel drug delivery system having characteristics like smaller particle size, higher drug loading, sustained drug release, high stability, increased cellular uptake and improved therapeutic potential. In the present study, we have formulated and characterized mixed PMs (MPMs) containing QCT for increasing its anticancer potential.

Methods: The MPMs were prepared by thin film hydration method, and their physicochemical properties were characterized. The in vitro anticancer activity of the MPMs were tested in breast (MCF-7 and MDA-MB-231, epithelial and metastatic cancer cell lines, respectively), and ovarian (SKOV-3 and NCI/ADR, epithelial and multi-drug resistant cell lines, respectively) cancer. Results: The optimal MPM formulations were obtained from Pluronic polymers, P123 and P407 with molar ratio of 7:3 (A16); and P123, P407 and TPGS in the molar ratio of 7:2:1 (A22). The size of the particles before lyophilization $(24.83 \pm 0.44 \mathrm{~nm})$ and after lyophilization $(37.10 \pm 4.23 \mathrm{~nm})$, drug loading $(8.75 \pm 0.41 \%)$, and encapsulation efficiency $(87.48 \pm 4.15 \%)$ for formulation A16 were determined. For formulation A22, the particle size before lyophilization, after lyophilization, drug loading and encapsulation efficiency were $26.37 \pm 2.19 \mathrm{~nm}$, $45.88 \pm 13.80 \mathrm{~nm}, 9.01 \pm 0.11 \%$ and $90.07 \pm 1.09 \%$, respectively. The MPMs exhibited sustained release of QCT compared to free QCT as demonstrated from in vitro release experiments. The solubility of QCT was markedly improved compared to pure QCT. The MPMs were highly stable in aqueous media as demonstrated by their low critical micelle concentration. The concentration which inhibited $50 \%$ growth $\left(\mathrm{IC}_{50}\right)$ values of both micellar preparations in all the cancer cell lines were significantly less compared to free QCT.

Conclusion: Both the MPMs containing QCT could be used for effective delivery to different type of cancer and may be considered for further development.

Keywords: quercetin, mixed polymeric micelle, Pluronics, TPGS, breast cancer, ovarian cancer, multidrug resistant cancer

\section{Introduction}

Quercetin (3,5,7,3',4'-pentahydroxyflavone, QCT) (Figure 1) is a polyphenolic compound that is present in many plants, fruits, and vegetables. ${ }^{1}$ It belongs to the flavonoid category, which is a class of polyphenolic compounds containing a basic skeleton of diphenylpropane and a common flavone moiety containing two benzene rings connected through a heterocyclic pyrole ring. ${ }^{2,3}$ QCT has a wide array of pharmacological applications including antioxidant, ${ }^{4,5}$ antidiabetic,${ }^{6}$ anti-inflammatory, ${ }^{7,8}$ and anti-proliferative ${ }^{9}$ 


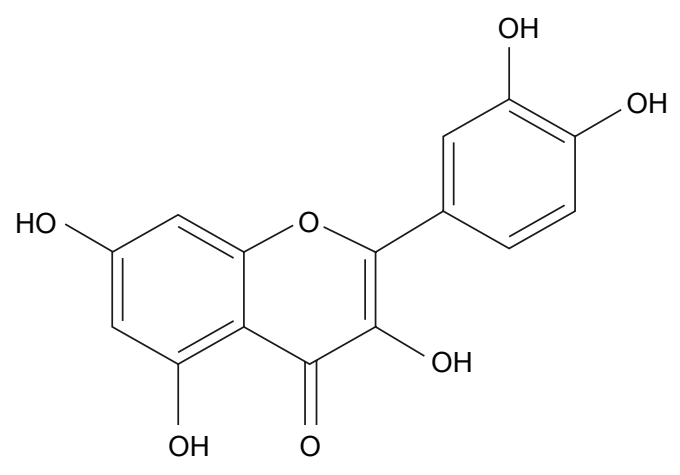

Figure I Chemical structure of quercetin.

activities. QCT shows anticancer activity by inhibiting growth of cancer cells through apoptosis and arresting cell cycle at $\mathrm{G} 2 / \mathrm{M}$ or $\mathrm{G} 1 / \mathrm{S}$ transitions by altering several targets. ${ }^{10-12}$ Other mechanisms that confer anticancer properties to QCT include: binding to type II receptors that are overexpressed in many tumors, ${ }^{13}$ direct binding with tubulin that induces depolymerization of microtubules, ${ }^{14}$ TRAIL $^{15}$ and PI3K-Akt/ PKB pathway mediated induction of apoptosis, inhibition of tumorigenesis and cancer progression, ${ }^{16}$ inhibition of tyrosine kinases that are involved in transduction of growth factor signals and oncogenesis, induction of p53 phosphorylation, and stabilization of p53 at both mRNA and protein level. ${ }^{12}$ Despite its pharmacological effects, the therapeutic application of QCT is limited greatly because of its low water solubility $(0.17-7.7 \mu \mathrm{g} / \mathrm{mL})^{17,18}$ and poor bioavailability (only $1 \%$ in humans and $<17 \%$ in rats). ${ }^{19}$ QCT was used earlier in clinical trials, but did not succeed because of the solvent used (dimethyl sulfoxide [DMSO] or ethanol) and efficacy loss with chemical modification. ${ }^{20,21}$ Various drug delivery systems have been developed to enhance the solubility and bioavailability of hydrophobic molecules for better therapeutic use. Nanotechnology serves as a novel drug delivery approach for lipophilic drugs. Nanoformulations could also be designed for passive targeting due to their enhanced permeability and retention effect owing to smaller size of the formulations and unique characteristics of tumor vasculature. ${ }^{22-24}$ Furthermore, in conjugation with targeting ligands, specific accumulation of the drug molecules in intracellular organelles, cancer cells, or organs with cancer could be achieved leading to active targeting. ${ }^{12}$ To enhance the anticancer potential of QCT, different nanodelivery approaches like micelles, ${ }^{17,25}$ polymeric nanoparticles, ${ }^{26,27}$ nanoemulsions, ${ }^{28}$ liposomes, ${ }^{21,29}$ and polymeric conjugates ${ }^{30,31}$ have been implemented.

Polymeric micelles (PMs) serve as a novel drug delivery system and possess characteristics like smaller particle size, higher drug loading (DL) capacity, sustained drug release, high stability, increased cellular uptake, and improved therapeutic potential. ${ }^{22,24,32-43}$ PMs with an amphiphilic polymer have limitations as the solubilization depends on the number of micelles in the system. The solubilization can be enhanced in mixed polymeric micelles (MPMs) by addition of extra hydrophobic material that provides more space for solubilization of poorly soluble drugs. ${ }^{25} \mathrm{MPMs}$ of some drugs such as paclitaxel, ${ }^{44}$ doxorubicin, ${ }^{45}$ curcumin, ${ }^{46}$ and gambogic acid ${ }^{47}$ have been explored to enhance the therapeutic potential. Zhao et al evaluated the in vitro anticancer effect of QCT-containing micelles (prepared from Pluronic P123 and tocopheryl polyethylene glycol succinate [TPGS]) in MCF-7 and MCF-7/ADR cell lines. ${ }^{17}$ However, they have not optimized the formulation parameters and the preparation was not lyophilized. Further, it was observed that the preparation produced a sticky mass after lyophilization and was not stable when stored at ambient temperature or $4^{\circ} \mathrm{C}$ or $-20^{\circ} \mathrm{C}$, which would be difficult for therapeutic utility. A more recent lecithin-based MPM delivery system prepared from Pluronic P123, QCT, lecithin, and 1,2-distearoyl-snglycero-3-phosphoethanolamine-N-methoxy [poly(ethylene glycol)-2000] was investigated for its anticancer potential in MCF-7 cell line. The particle size of the formulation was $61.60 \pm 5.02 \mathrm{~nm}$ with a high size distribution of $0.589 \pm 0.198 .^{25}$ The current study was undertaken to formulate MPMs for delivery of QCT, their characterization, and in vitro evaluation of optimized preparations against breast, ovarian, and multidrug resistant cancer cells.

\section{Materials and methods Chemicals and reagents}

Quercetin dihydrate (QCT) and iodine were purchased from Alfa Aesar (Haverhill, MA, USA); Pluronic ${ }^{\circledR}$ P 123 (P123), Kolliphor ${ }^{\circledR}$ TPGS (TPGS), Pluronic ${ }^{\circledR}$ L 92 (L92), and Kolliphor P 407 (P407) were gifted by BASF Corporation (Florham Park, NJ, USA). DMEM media, RPMI 1640 media, trypsin, DMSO, and PBS were procured from Mediatech Inc. (Manassas, VA, USA). Tween 80 and MTT were obtained from Sigma-Aldrich Co. (St Louis, MO, USA). Potassium iodide was obtained from Ameresco (Solon, OH, USA). In all the experiments, Millipore ultrapure water was used.

\section{Preparation of QCT-loaded MPMs}

QCT-containing MPMs were fabricated by thin-film hydration method as described earlier, with some modifications. ${ }^{46,47}$ Briefly, various polymers of $10 \mathrm{mM}$ concentration at different proportions with QCT were dissolved in ethanol (Alfa Aesar). The solvent was removed under low pressure, in a rotary vacuum evaporator set at a temperature of $40^{\circ} \mathrm{C}$ for $1 \mathrm{~h}$, to get a thin film of a mixture of QCT and polymers. 
To remove any residual ethanol, the thin film was subject to further drying under vacuum at room temperature for $24 \mathrm{~h}$. Then, $3 \mathrm{~mL}$ of water was added to the thin film and shaken at room temperature to form micelles. The resultant micelles were then centrifuged at 10,000 rpm for $10 \mathrm{~min}$ (Allegra ${ }^{\mathrm{TM}}$ 25R Centrifuge; Beckman Coulter, Brea, CA, USA) followed by filtration of the supernatant using a $0.2 \mu \mathrm{m}$ cellulose acetate membrane filter (VWR International, Radnor, PA, USA) to remove the unincorporated QCT aggregates. The mixed micellar solution was kept at $-80^{\circ} \mathrm{C}$ for $2 \mathrm{~h}$ and then lyophilized (FreeZone ${ }^{\circledR}$ Plus ${ }^{\mathrm{TM}}$; Labconco Corporation, Kansas City, MO, USA) for 18 h. Similarly, empty mixed micelles (without QCT) were also fabricated.

\section{Determination of particle size and zeta potential}

The average size of the micelles and their polydispersity index (PDI) (size distribution) were determined by dynamic light scattering method (NanoBrook 90 Plus PALS; Brookhaven Instruments, Holtsville, NY, USA). Cell temperature was $25^{\circ} \mathrm{C}$ with a detection angle of $90^{\circ}$. All measurements were performed in triplicate after appropriate dilution using deionized (DI) water. Particle size and PDI were measured both before and after lyophilization. The same instrument was used to measure zeta potential. All experiments were carried out in triplicate and the data are represented as mean \pm standard deviation (SD).

\section{Drug loading and encapsulation efficiency} After lyophilization, $1.0 \mathrm{mg}$ of PMs was accurately weighed in an amber colored glass vial. To the vial $1 \mathrm{~mL}$ of ethanol was added, sonicated for 2-3 min, and left in the dark for $1 \mathrm{~h}$ at room temperature, and then the ultraviolet (UV) absorbance of the samples was measured at $373 \mathrm{~nm}$ (Varioskan Flash; Thermo Fisher Scientific, Waltham, MA, USA). A suitable blank was used for spectrophotometric measurements. Encapsulation efficiency (EE) was calculated based on the weight of QCT in the prepared micelles over the initial amount of QCT used to prepare the micelles. Similarly, DL was calculated by comparing the weight of QCT in the micelles to the total quantity of QCT and polymer used for the preparation of the formulation. The equations for determining percentage EE and DL are as follows:

$$
\begin{gathered}
\% \mathrm{EE}=\frac{\text { Weight of QCT in the micelles }}{\text { Weight of initial amount of QCT }} \times 100 \\
\% \mathrm{DL}=\frac{\text { Weight of QCT in the micelles }}{\text { Weight of polymer and QCT taken }} \times 100
\end{gathered}
$$

\section{Critical micelle concentration (CMC)}

CMC of mixture of polymers P123/P407 (7:3) and P123/P407/TPGS (7:2:1) in DI water was determined by UV-vis spectrophotometry (Varioskan Flash; Thermo Fisher Scientific) at $366 \mathrm{~nm}$ using iodine as a hydrophobic probe. ${ }^{44,47}$ About $0.5 \mathrm{~g}$ of iodine $\left(\mathrm{I}_{2}\right)$ and $1.0 \mathrm{~g}$ of potassium iodide $(\mathrm{KI})$ were dissolved in $50 \mathrm{~mL}$ of $\mathrm{DI}$ water to prepare the $\mathrm{KI} / \mathrm{I}_{2}$ standard solution. Different concentrations (in the range of $0.00001 \%-0.1 \%$ ) of the above mixture of polymers were prepared. Twenty-five microliters of $\mathrm{KI} / \mathrm{I}_{2}$ standard solution was added to each of the polymer mixtures of various concentrations. The mixtures were left in the dark at room temperature for $12 \mathrm{~h}$ and then the absorbance was measured at $366 \mathrm{~nm}$. Each experiment was repeated three times and the average absorbance was determined. The absorbance and the logarithm of polymer concentration were plotted. The CMC value of the polymer mixture corresponds to the polymer concentration when a rapid increase in the absorbance was observed.

\section{Solubility of QCT in water and polymeric micellar solution}

Excess amount of QCT powder was added to $5.0 \mathrm{~mL}$ of DI water and mixed well by stirring at $100 \mathrm{rpm}$ at $25^{\circ} \mathrm{C}$ for $72 \mathrm{~h}$ on a horizontal shaker (VWR International) followed by centrifugation at $15,000 \mathrm{rpm}$ for $15 \mathrm{~min}$. The supernatant was filtered through a $0.2 \mu \mathrm{m}$ membrane filter and the amount of QCT in the filtrate was analyzed by measuring the absorbance at $373 \mathrm{~nm}$. For determining the solubility of QCT in the micellar solution, $50 \mu \mathrm{L}$ of the micellar solution obtained after hydration, centrifugation, and filtration was suitably diluted with alcohol. The amount of QCT in the diluted solution was determined from UV absorbance at $373 \mathrm{~nm}$, and the solubility of QCT in the PMs was calculated. ${ }^{17}$

\section{In vitro drug release}

The prepared micelles (A16 and A22) containing 1,500 $\mu \mathrm{g}$ of QCT were suspended in $0.5 \mathrm{~mL}$ of PBS by slight vortexing and placed in a dialysis bag (Spectra/Por ${ }^{\circledR}$ MolecularPorous Membrane Tubing, flat width $23 \mathrm{~mm}$, diameter $14.6 \mathrm{~mm}$, MWCO 6-8,000; Spectrum Laboratories Inc., Rancho Dominguez, CA, USA) to determine in vitro release of QCT. The bag was closed on both sides with clips, and immersed in a glass container containing $100 \mathrm{~mL}$ of release medium (PBS with $0.5 \%$ Tween 80, pH 7.4). The container was placed in a horizontal shaking incubator (VWR International) at $37^{\circ} \mathrm{C}$ and $100 \mathrm{rpm}$. About $1.0 \mathrm{~mL}$ of the release medium was withdrawn at different time intervals, and the amount of QCT was determined from the UV absorption at $337 \mathrm{~nm}$. 
During the initial $8 \mathrm{~h}$ of sampling, the withdrawn release medium was replaced with fresh buffer. Afterward, release medium was completely replaced each time with fresh buffer after sample collection. Under similar conditions, release of QCT from propylene glycol was also carried out and compared with release of QCT from the micelles. ${ }^{17,25}$ Percentage cumulative release of QCT at different time intervals was calculated from the equation:

$\%$ cumulative release

$$
=\frac{\text { Amount of QCT in the medium }(\mu \mathrm{g})}{\text { Amount of QCT loaded in the micelles }(\mu \mathrm{g})} \times 100
$$

\section{Determination of total antioxidant capacity}

Total antioxidant capacity (TAC) of pure QCT, A16, and A22 was determined using OxiSelect ${ }^{\mathrm{TM}}$ TAC Assay Kit (Catalog number: STA-360; Cell Biolabs, Inc., San Diego, CA, USA) which measures the TAC of samples via a single electron transfer mechanism. ${ }^{48}$ The kit components were uric acid standard (Part No 236001), reaction buffer (100X) (Part No 236002), copper ion reagent (100X) (Part No 236003), and stop solution (10X) (Part No 236004). This method is based on the reduction of copper (II) to copper (I) by antioxidants such as uric acid. After reduction, the copper (I) ion could react with a coupling chromogenic reagent that produces a color with maximum absorbance at $490 \mathrm{~nm}$. The antioxidant potential of a sample is compared with uric acid standard curve. The assay process was carried out following the manufacturer's product manual and TAC was expressed as $\mu \mathrm{M}$ copper reducing equivalents (CREs). Briefly, $20 \mu \mathrm{L}$ of different concentrations of sample and $180 \mu \mathrm{L}$ of $1 \mathrm{X}$ reaction buffer were added to each well in a 96-well plate and mixed thoroughly. The initial absorbance was measured at $490 \mathrm{~nm}$. The initiation of the reaction was done by adding $50 \mu \mathrm{L}$ of $1 \mathrm{X}$ copper ion reagent into each well and incubating for $5 \mathrm{~min}$ on an orbital shaker. The reaction was terminated by addition of $50 \mu \mathrm{L}$ of $1 \mathrm{X}$ stop solution to each well. The absorbance was determined again. The actual absorbance was calculated by subtracting the initial reading from the final reading and the $\mathrm{mM}$ uric acid equivalent (UAE) was determined from the uric acid standard curve (range: 0-1.0 mM). Finally, CRE was determined by multiplying UAE concentration by 2,189 .

\section{Cell culture}

The SKOV-3 (ovarian), NCI/ADR (multidrug resistant), MCF-7 and MDA-MB-231 (breast) cancer cells were purchased from ATCC (Manassas, VA, USA). Ovarian and breast cancer cells were grown in Dulbecco's Modified Eagle's Medium (DMEM), and multidrug resistant cancer cell lines were cultured in RPMI 1640 media complemented with $10 \%$ fetal bovine serum and $1 \%$ penicillin/ streptomycin (penicillin/streptomycin solution [100X] with $10,000 \mathrm{IU} / \mathrm{mL}$ penicillin and $10,000 \mu \mathrm{g} / \mathrm{mL}$ streptomycin) (Mediatech). Cells were trypsinized and passaged upon confluence.

\section{In vitro cytotoxicity study}

The in vitro anticancer activity of QCT, A16, A22, and empty micelles was evaluated using the MTT assay. In short, MCF-7 $\left(3 \times 10^{3}\right.$ cells/well), MBA-MD-231 $\left(3 \times 10^{3}\right.$ cells/well), SKOV-3 $\left(3 \times 10^{3}\right.$ cells/well $)$, and NCI/ADR $\left(4 \times 10^{3}\right.$ cells/well) cells were moved to 96 -well tissue culture plates. After $24 \mathrm{~h}$, the medium was removed and replaced with fresh medium containing QCT, A16, A22, and empty micelles at different concentrations. Control wells had only fresh culture media. The 96-well plates were incubated for $72 \mathrm{~h}$ at $37^{\circ} \mathrm{C}$ and $5 \% \mathrm{CO}_{2}$. Then, the medium was removed and cells in each well were gently washed twice with sterile PBS (1X). Fifty (50) $\mu \mathrm{L}$ of MTT solution $(0.5 \mathrm{mg} / \mathrm{mL})$ was added to each well and again incubated for $4 \mathrm{~h}$ at $37^{\circ} \mathrm{C}$ and $5 \% \mathrm{CO}_{2}$. After $4 \mathrm{~h}$, the medium was removed and $100 \mu \mathrm{L}$ of DMSO was added to each well to dissolve the purple formazan crystals. Viability of the cells was determined by measurement of the absorbance at $570 \mathrm{~nm}$ by a microplate reader (Varioskan Flash). The concentration which inhibited $50 \%$ growth $\left(\mathrm{IC}_{50}\right)$ was calculated using GraphPad Prism 7.0 (GraphPad Software, La Jolla, CA, USA) software, and percentage cell viability with different treatments was also determined.

$$
\% \text { cell viability }=\frac{\text { Absorbance of treatment group }}{\text { Absorbance of control group }} \times 100
$$

\section{Statistical analysis}

Data are represented as mean \pm standard deviation (SD). Student's $t$-test was used for statistical analysis of the data in the release study. The data obtained from in vitro antioxidant and cytotoxicity studies were subjected to one-way analysis of variance (ANOVA) followed by post hoc Newman-Keuls multiple comparisons for significance using GraphPad Prism 7.0 software. $P<0.05$ was considered as statistically significant. 


\section{Results and discussion Preparation of QCT-loaded MPMs}

Pluronic block copolymers consist of polyethylene oxide (PEO) (hydrophilic) and polypropylene oxide (PPO) (hydrophobic) blocks arranged in PEO-PPO-PEO structure. During hydration of the thin film, these copolymers self-assemble into micelles at a concentration above CMC. ${ }^{49}$ The central core of these micelles comprises a hydrophobic PPO block and an outer shell composed of a hydrophilic PEO block. The PPO core enhances the incorporation of water-insoluble drugs, and the outer shell shelters the drug from the aqueous environment, stabilizes the micelles from recognition in vivo by the reticuloendothelial system, and controls in vivo pharmacokinetic properties. Micelle preparations increase the metabolic stability, solubility, and circulation time of the encapsulated hydrophobic drugs. ${ }^{47,50,51}$ TPGS is used as a surfactant for lipophilic drugs and as an enhancer of absorption and bioavailability. ${ }^{52,53}$ In the present study, solubility of QCT was increased by incorporating TPGS into micelles.

Initially, the micelles were prepared with the BoxBehnken experimental design by considering three variables in three different levels (Table 1). The Pluronics were selected based on their molecular weight, average number of PPO units, and hydrophilic-lipophilic balance (HLB) value because the P-glycoprotein (P-gp) inhibition property of Pluronics depends on their HLB value and effective number of PPO units. The molecular weight, average number of PPO units, and HLB value of L92, P123, and P407 are also shown in Table 1. The formulations (A1-A15) were prepared and observed for various physicochemical characteristics (Table 2). It was observed that the formulations were not stable when stored in the solution form at room temperature or $4^{\circ} \mathrm{C}$ or $-20^{\circ} \mathrm{C}$ as QCT comes out of the inner core. Solid puffy mass after lyophilization was obtained only if the formulation had P407, which may be attributed to the solid nature of P407. Puronic P123 and L92 are liquids at

Table I Different variables and their levels for micelle preparation

\begin{tabular}{llll}
\hline Level & Variable & & \\
\cline { 2 - 4 } & Pluronics & $\begin{array}{l}\% \text { of } \\
\text { QCT }\end{array}$ & $\begin{array}{l}\text { Molar ratio } \\
\text { of Pluronic } \\
\text { and TPGS }\end{array}$ \\
\hline I & L92 (MW: 3,650, PO: 50.34, HLB: 6) & 10 & $10: 0$ \\
2 & PI23 (MW: 5,750, PO: 69.40, HLB: 8) & 15 & $7: 3$ \\
3 & P407 (MW: 12,650, PO: 65.17, HLB: 22) & 20 & $5: 5$ \\
\hline
\end{tabular}

Abbreviations: MW, molecular weight; $\mathrm{PO}$, propylene oxide; HLB, hydrophiliclipophilic balance; QCT, quercetin; TPGS, tocopheryl polyethylene glycol succinate. room temperature, and formulations with these polymers produced a sticky mass after lyophilization. Formulation A5, A7, A10, and A15 produced a clear micellar solution after hydration of the thin film indicating higher drug encapsulation in the presence of P123, while other formulations were cloudy solutions. The percentage DL and EE were deemed as satisfactory with formulations comprising P123 or L92, and $10 \%$ initial DL was preferred. Based on these findings, we prepared and characterized additional formulations with different combinations of P123/P407 and L92/P407 with or without TPGS to get a preparation with smaller particle size and high EE (Table 3). The DL and EE of the formulations containing higher molar ratio of $\mathrm{P} 123$ or $\mathrm{L} 92$ were better, but the particle size was larger in formulations with L92. Finally, formulations A16 and A22 were selected for further studies by considering their DL, EE, particle size, and PDI before and after lyophilization. Both A16 and A22 were clear solutions compared to the suspension of pure QCT in water at the same drug concentration (Figure 2). A16 and A22 formulations were stable for 2.5 months (preliminary study) when stored at $-20^{\circ} \mathrm{C}$ without any significant difference in their particle size, DL, and EE.

\section{Characterization of QCT-loaded micelles} Particle size, size distribution, and zeta potential

The mean particle size of A16 before and after lyophilization was $24.83 \pm 0.44 \mathrm{~nm}$ and $37.10 \pm 4.23 \mathrm{~nm}$ (Figure 3), respectively. For A22, the mean particle size before and after lyophilization was $26.37 \pm 2.19 \mathrm{~nm}$ and $45.88 \pm 13.80 \mathrm{~nm}$, respectively (Figure 4). A small but insignificant increase in particle size was demonstrated in the formulation A22 containing TPGS both before and after lyophilization. The percentage increase in particle size after lyophilization in A16 and A22 was 49.4 and 73.9\%, respectively. The PDI values before and after lyophilization were low in both formulations (Table 3). Earlier studies reported that Pluronic micelles containing QCT are spherical. ${ }^{17,25}$ The zeta potential of A16 and A22 was $-11.72 \pm 2.24$ and $-12.28 \pm 3.52 \mathrm{mV}$, respectively (Figure 5). PPO and PEO parts in both P123 and P407 are nonionic, hence the surface charge in the mixed micelles should be attributed to addition of QCT and/or TPGS. The anionic property of the mixed micelles might be due to dissociation of the acidic phenolic group of QCT. ${ }^{54}$ Further, the increase of negative surface charge in A22 might have resulted from addition of TPGS, which increased the solubility of QCT yielding more anionic QCT in the solution. ${ }^{17,47}$ In addition, the empty micelles show 
Table 2 Physicochemical characters of different QCT-loaded mixed polymeric micelles

\begin{tabular}{|c|c|c|c|c|c|c|c|c|}
\hline Formulation & Polymer ratios & $\begin{array}{l}\text { Quercetin } \\
\text { (\%) }\end{array}$ & $\begin{array}{l}\text { Drug } \\
\text { loading } \\
(\%)\end{array}$ & $\begin{array}{l}\text { Encapsulation } \\
\text { efficiency (\%) }\end{array}$ & $\begin{array}{l}\text { Particle size }(\mathrm{nm}) \\
\text { after centrifugation } \\
(10,000 \mathrm{rpm}, \\
10 \mathrm{~min}) \text { and } \\
\text { filtration }\end{array}$ & PDI & $\begin{array}{l}\text { Appearance } \\
\text { after storage } \\
\left(-80^{\circ} \mathrm{C} \text {, }\right. \\
2 \text { weeks) }\end{array}$ & $\begin{array}{l}\text { Appearance } \\
\text { after } \\
\text { lyophilization }\end{array}$ \\
\hline Al & P407:TPGS (5:5) & 15 & 3.07 & 20.45 & $19.74 \pm 0.65$ & $0.189 \pm 0.008$ & Cloudy & Puffy solid mass \\
\hline $\mathrm{A} 2$ & L92:TPGS (5:5) & 15 & 5.52 & 36.83 & $119.56 \pm 2.04$ & $0.184 \pm 0.014$ & Cloudy & Sticky mass \\
\hline A3 & P407:TPGS (7:3) & 20 & 2.95 & 14.74 & $108.51 \pm 29.54$ & $0.226 \pm 0.049$ & Cloudy & Puffy solid mass \\
\hline A4 & L92:TPGS (7:3) & 10 & 7.57 & 75.75 & $|78.42 \pm| .78$ & $0.183 \pm 0.011$ & Cloudy & Sticky mass \\
\hline A5 & PI23:TPGS (7:3) & 15 & 10.20 & 68.01 & $88.56 \pm 1.11$ & $0.209 \pm 0.011$ & Cloudy & Sticky mass \\
\hline A6 & L92:TPGS (10:0) & 15 & 12.95 & 86.39 & $403.20 \pm 140.98$ & $0.267 \pm 0.060$ & Cloudy & Sticky mass \\
\hline A7 & PI23:TPGS (I0:0) & 10 & 9.47 & 94.77 & $82.40 \pm 0.98$ & $0.235 \pm 0.011$ & Cloudy & Sticky mass \\
\hline A8 & P407:TPGS (7:3) & 10 & 3.5 & 35.05 & $38.45 \pm 10.6$ & $0.326 \pm 0.030$ & Cloudy & Puffy solid mass \\
\hline A9 & PI23:TPGS (I0:0) & 20 & 11.21 & 56.56 & $113.62 \pm 0.78$ & $0.192 \pm 0.002$ & Cloudy & Sticky mass \\
\hline AlO & PI23:TPGS (7:3) & 15 & 10.09 & 67.32 & $104.76 \pm 1.63$ & $0.277 \pm 0.006$ & Cloudy & Sticky mass \\
\hline All & L92:TPGS (7:3) & 20 & 10.14 & 50.72 & $168.43 \pm 22.74$ & $0.191 \pm 0.013$ & Cloudy & Sticky mass \\
\hline $\mathrm{A} / 2$ & P407:TPGS (10:0) & 15 & 2.99 & 19.94 & $101.5 \pm 16.36$ & $0.339 \pm 0.032$ & Cloudy & Puffy solid mass \\
\hline $\mathrm{A} / 3$ & PI23:TPGS (5:5) & 20 & 8.86 & 44.33 & $25.07 \pm 2.56$ & $0.213 \pm 0.016$ & Cloudy & Sticky mass \\
\hline $\mathrm{A} / 4$ & PI23:TPGS (5:5) & 10 & 7.90 & 79.04 & $18.66 \pm 0.12$ & $0.157 \pm 0.010$ & Cloudy & Sticky mass \\
\hline Al5 & PI23:TPGS (7:3) & 15 & 12.88 & 86.07 & $95.59 \pm 1.19$ & $0.235 \pm 0.003$ & Cloudy & Sticky mass \\
\hline
\end{tabular}

Abbreviations: QCT, quercetin; PDI, polydispersity index; TPGS, tocopheryl polyethylene glycol succinate.

negative zeta potential ${ }^{47}$ confirming the formation of charge during formulation of micelles.

\section{Drug loading and encapsulation efficiency} The DL andEE of A16 were $8.75 \% \pm 0.41 \%$ and $87.48 \% \pm 4.15 \%$, respectively. For A22, the DL and EE were 9.01\% $0.11 \%$ and $90.07 \% \pm 1.09 \%$, respectively. The DL and EE slightly increased with TPGS in the preparation A22 compared to formulation without TPGS. The increase is due to the TPGS property to enhance solubility of hydrophobic drugs. Additionally, TPGS is approved by US Food and Drug Administration for different drug delivery systems. ${ }^{55}$ Furthermore, the DL and EE were influenced by the nature and concentration of polymers, nature and length of the core forming block, and length of shell forming blocks in the micelle. ${ }^{56}$ Increased DL and EE in A22 might be due to stable reactions of the TPGS aromatic ring, PPO group of Pluronics, and/or encapsulated drug. ${ }^{17}$

Table 3 Physicochemical characteristics of different QCT-loaded mixed polymeric micelles with combinations of PI23/P407 and L92/ P407 with or without TPGS

\begin{tabular}{|c|c|c|c|c|c|c|c|c|}
\hline Formulation & Polymer ratios & $\begin{array}{l}\text { Quercetin } \\
\text { (\%) }\end{array}$ & $\begin{array}{l}\text { Drug } \\
\text { loading } \\
(\%)\end{array}$ & $\begin{array}{l}\text { Encapsulation } \\
\text { efficiency (\%) }\end{array}$ & $\begin{array}{l}\text { Particle } \\
\text { size }(\mathrm{nm}) \text { after } \\
\text { centrifugation } \\
(10,000 \mathrm{rpm}, \\
10 \mathrm{~min}) \text { and } \\
\text { filtration }\end{array}$ & PDI & $\begin{array}{l}\text { Particle } \\
\text { size after } \\
\text { lyophilization }\end{array}$ & $\begin{array}{l}\text { PDI after } \\
\text { lyophilization }\end{array}$ \\
\hline Al6 & PI23:P407 (7:3) & 10 & $8.75 \pm 0.4 I$ & $87.48 \pm 4.15$ & $24.83 \pm 0.44$ & $0.106 \pm 0.044$ & $37.10 \pm 4.23$ & $0.136 \pm 0.036$ \\
\hline Al7 & PI23:P407 (5:5) & 10 & $3.83 \pm 0.52$ & $38.28 \pm 5.26$ & $25.96 \pm 0.12$ & $0.178 \pm 0.040$ & $188.36 \pm 79.45$ & $0.852 \pm 0.070$ \\
\hline Al8 & PI23:P407 (3:7) & 10 & $5.02 \pm 0.6 \mathrm{I}$ & $50.25 \pm 6.14$ & $26.18 \pm 0.18$ & $0.112 \pm 0.010$ & $37.28 \pm 5.12$ & $0.324 \pm 0.025$ \\
\hline Al9 & L92:P407 (7:3) & 10 & $7.85 \pm 0.62$ & $78.53 \pm 6.27$ & $816.63 \pm 142.38$ & $0.226 \pm 0.04 I$ & $99.15 \pm 2.57$ & $0.274 \pm 0.006$ \\
\hline A20 & L92:P407 (5:5) & 10 & $8.03 \pm 0.41$ & $80.28 \pm 4.13$ & $511.50 \pm 297.69$ & $0.199 \pm 0.057$ & $2,356.37 \pm 555.0 \mathrm{I}$ & $0.633 \pm 0.025$ \\
\hline A2I & L92:P407 (3:7) & 10 & $4.19 \pm 0.71$ & $41.94 \pm 7.16$ & $2,858.57 \pm 1,192.54$ & $0.391 \pm 0.016$ & $3,453.28 \pm 691.10$ & $0.500 \pm 0.075$ \\
\hline A22 & $\begin{array}{l}\text { PI23:P407:TPGS } \\
(7: 2: 1)\end{array}$ & 10 & $9.01 \pm 0.11$ & $90.07 \pm 1.09$ & $26.37 \pm 2.19$ & $0.204 \pm 0.036$ & $45.88 \pm 13.80$ & $0.277 \pm 0.004$ \\
\hline A23 & $\begin{array}{l}\text { L92:P407:TPGS } \\
(7: 2: 1)\end{array}$ & 10 & $8.50 \pm 0.23$ & $84.98 \pm 2.34$ & $121.94 \pm 12.87$ & $0.199 \pm 0.020$ & $266.40 \pm 262.08$ & $0.279 \pm 0.056$ \\
\hline A24 & $\begin{array}{l}\text { L92:P407:TPGS } \\
(5: 3: 2)\end{array}$ & 10 & $8.55 \pm 0.27$ & $85.54 \pm 2.74$ & $297.13 \pm 147.29$ & $0.209 \pm 0.063$ & $902.13 \pm 459.95$ & $0.253 \pm 0.114$ \\
\hline
\end{tabular}

Abbreviations: QCT, quercetin; PDI, polydispersity index; TPGS, tocopheryl polyethylene glycol succinate. 

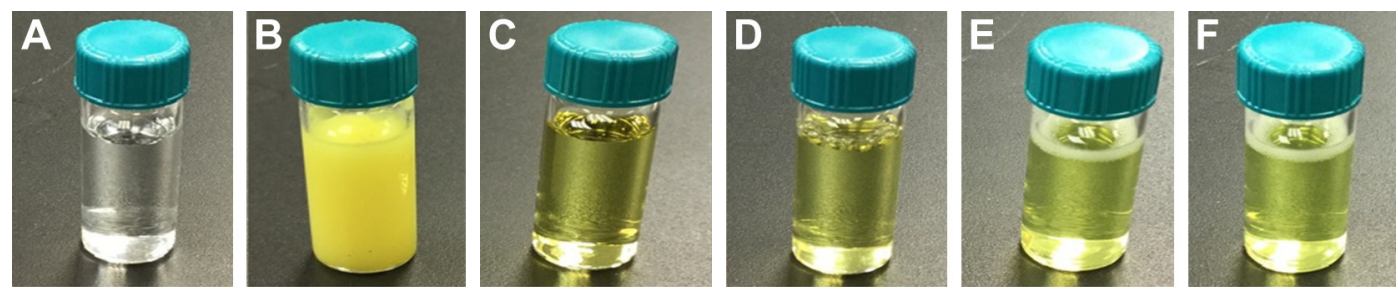

Figure 2 Photographs of QCT-loaded mixed polymeric micelles. A: Millipore water, B: $10 \mathrm{mg}$ pure QCT in $3 \mathrm{~mL}$ of Millipore water, C: formulation Al6 immediately after centrifugation and filtration through $0.2 \mu \mathrm{m}$ membrane filter, $\mathbf{D}$ : formulation A22 immediately after centrifugation and filtration through $0.2 \mu \mathrm{m}$ membrane filter, E: lyophilized formulation of A16 suspended in $3 \mathrm{~mL}$ of Millipore water, and F: lyophilized formulation of A22 suspended in $3 \mathrm{~mL}$ of Millipore water.

Abbreviation: $\mathrm{QCT}$, quercetin.

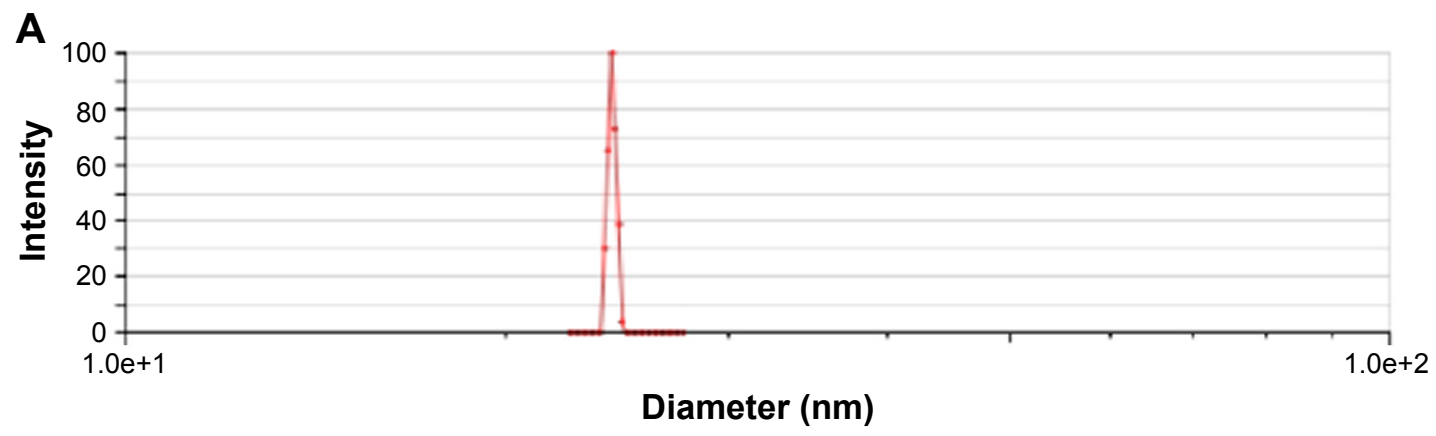

B

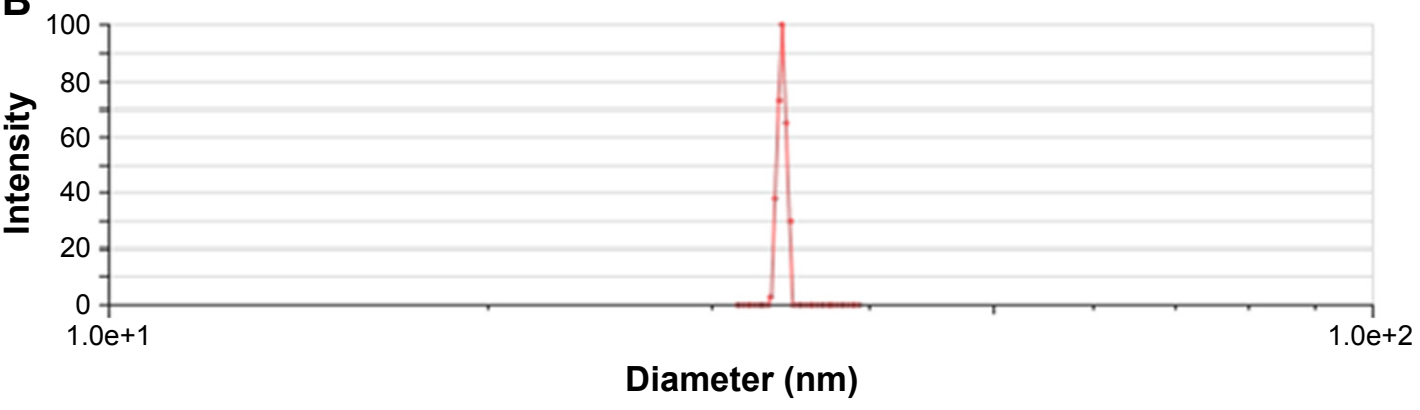

Figure 3 Particle size of A 16 before lyophilization (A) and after lyophilization (B).

A

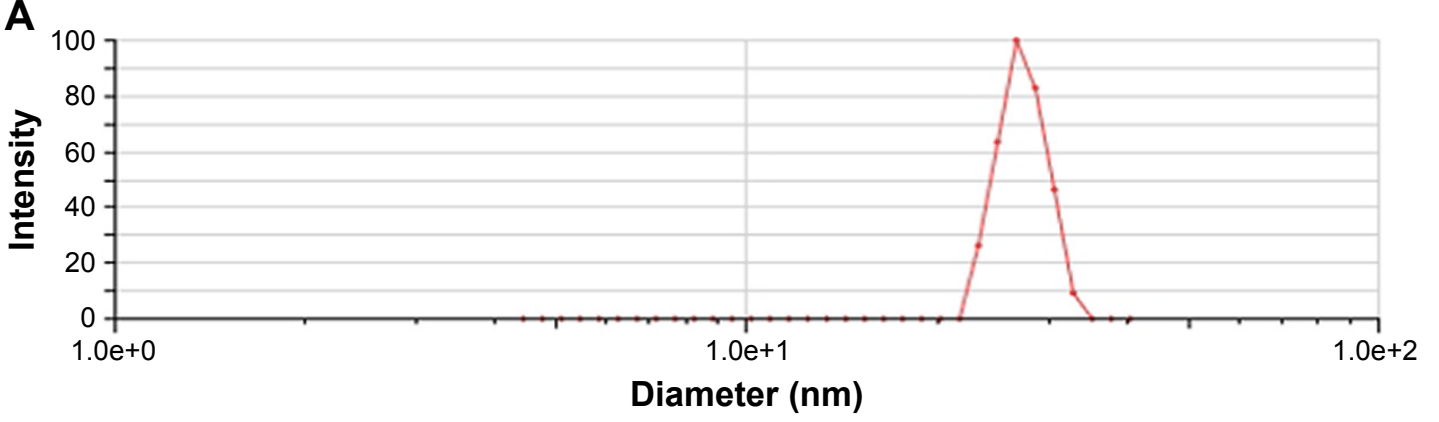

B

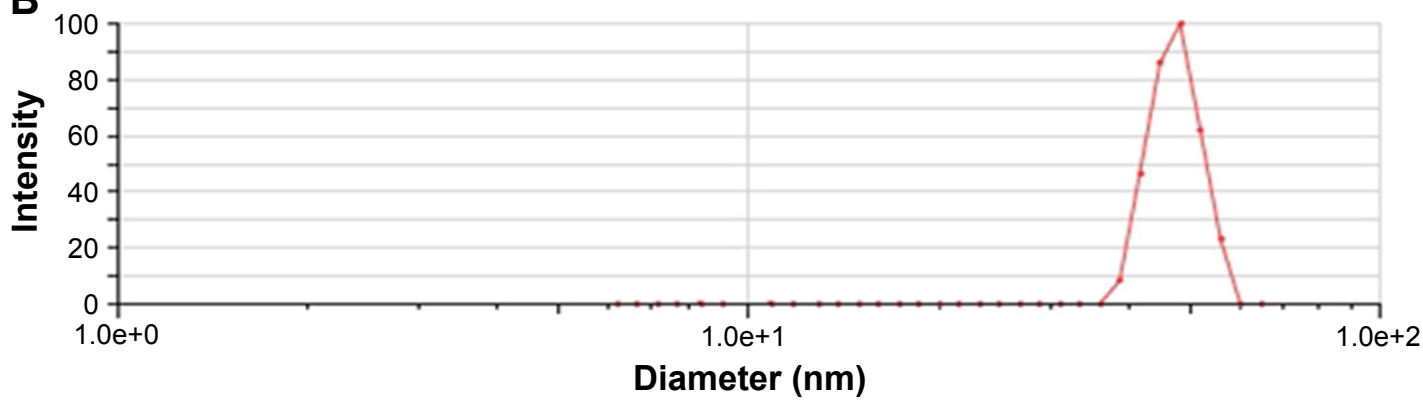

Figure 4 Particle size of A22 before lyophilization (A) and after lyophilization (B). 


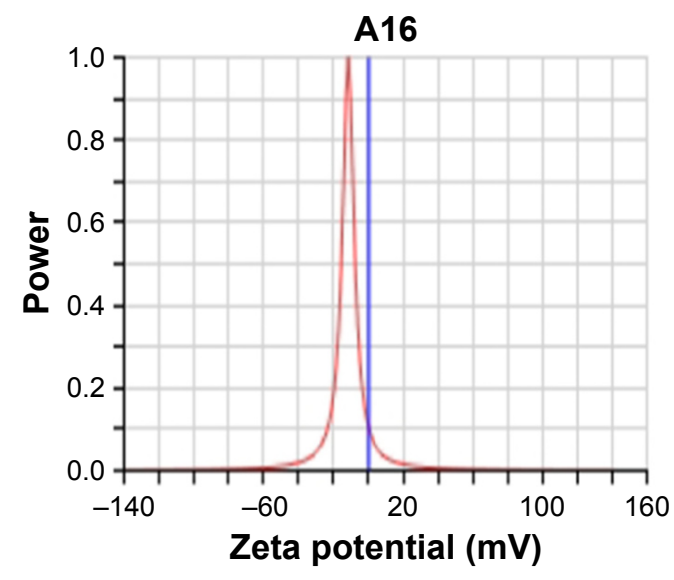

Figure 5 Zeta potential of A16 and A22.

The solubility of QCT in water was $2.18 \mu \mathrm{g} / \mathrm{mL}$, while in A16 and A22 the solubility was $7,590 \mu \mathrm{g} / \mathrm{mL}$ and $6,704 \mu \mathrm{g} / \mathrm{mL}$, respectively. Therefore, the solubility of QCT was 1,161- and 1,025-fold higher in A16 and A22, respectively, compared to pure QCT in water.

\section{Critical micelle concentration}

Pluronic block copolymers consisting of PEO and PPO blocks self-assemble into micelles in aqueous solutions, ${ }^{57}$ which are formed above CMC. Hence, CMC influences the in vitro and in vivo stability of the micelles. In the present study, CMC was measured by using iodine as a hydrophobic probe. Solubilized iodine participates in the hydrophobic microenvironment of Pluronic copolymers, causing the conversion of $\mathrm{I}_{3}^{-}$to $\mathrm{I}_{2}$ from the surplus potassium iodide present in the solution. CMC was calculated by plotting the absorbance intensity of $\mathrm{I}_{2}$ versus $\log$ of the polymer concentration (\%wt). The CMC of micellar solution of P123/P407 (7:3 molar ratio) in A16 was found to

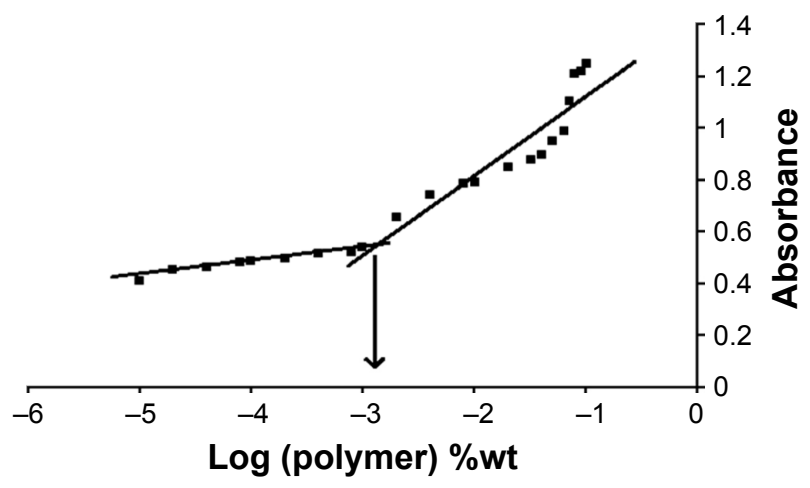

Figure $6 \mathrm{UV}$ absorbance of $\mathrm{I}_{2}$ versus concentration of PI23/P407 mixed mecelles (7:3 molar ratio) in water. CMC was measured by the corresponding polymer concentration when a rapid increase in absorbance was seen.

Note: $x$-axis represents the logarithm of polymer concentration (percent weight). Abbreviations: CMC, critical micelle concentration; UV, ultraviolet.

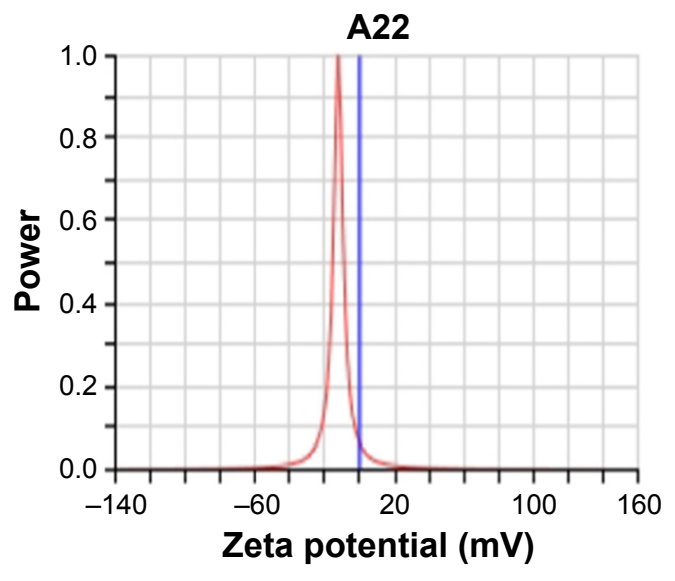

be $0.0015 \% \mathrm{w} / \mathrm{v}$ (Figure 6). Addition of TPGS during A22 preparation did not show any significant variation in the CMC. The mixed micelles may be highly stable and may maintain integrity after dilution in the body as evidenced from their low CMC value. ${ }^{47}$

\section{In vitro drug release}

The in vitro QCT release from the MPMs was studied by dialysis method using PBS with $0.5 \%$ Tween 80 as release medium to get the sink condition. After $8 \mathrm{~h}$, the percentage QCT released from A16 and A22 was $12 \%$ and $30 \%$, respectively, while most of the QCT from the propylene glycol solution was dissolved (Figure 7). After 5 days, 97\% of QCT was released from A22 mixed micelles which contain TPGS, whereas the release of QCT from A16 was only $75 \%$. After 7 days, $17 \%$ of initially incorporated QCT still remained in the A16 micellar

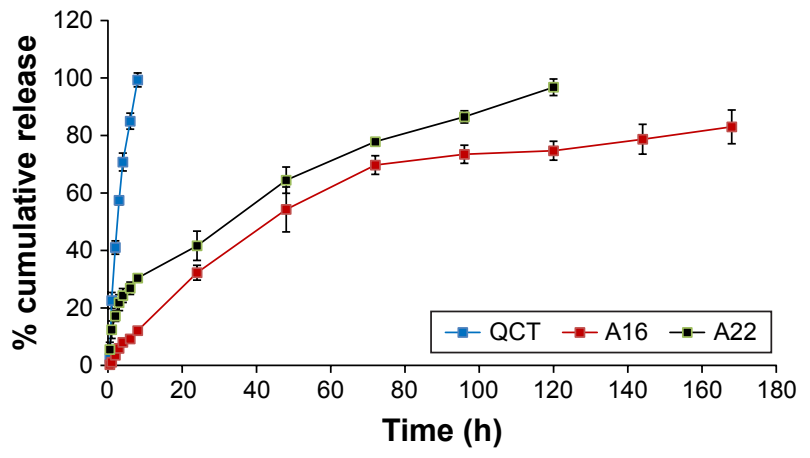

Figure 7 In vitro release profile of QCT from formulations (A16, A22) and control QCT solution (in propylene glycol) using dialysis bags containing the control QCT solution or formulations. The release study was performed at $37^{\circ} \mathrm{C}$ at $100 \mathrm{rpm}$ in IX PBS containing $0.5 \%$ Tween $80, \mathrm{pH} 7.4$. Values are mean \pm SD $(n=3)$. AI6, mixed polymeric micelles of PI23/P407 (7:3 molar ratio) containing QCT; A22, mixed polymeric micelles of PI23/P407/TPGS (7:2:1 molar ratio) containing QCT. The release of QCT from A22 was significantly higher $(P<0.05)$ compared to A16 at different time intervals, except at $48 \mathrm{~h}$.

Abbreviations: PBS, phosphate buffer saline; QCT, quercetin; TPGS, tocopheryl polyethylene glycol succinate. 


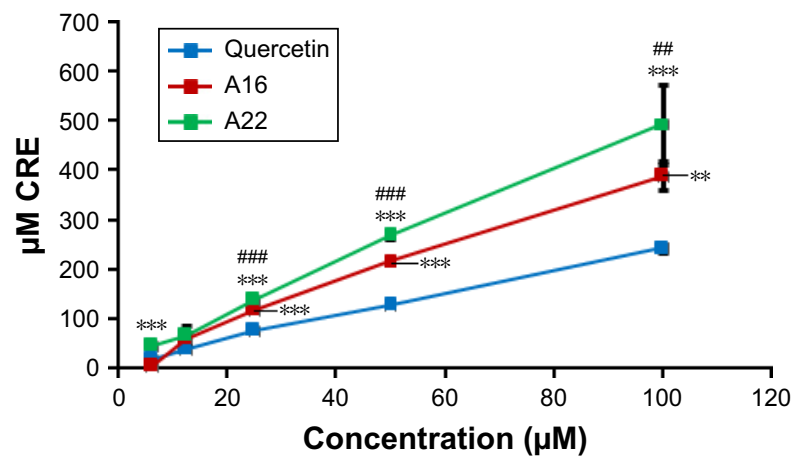

Figure 8 Total antioxidant capacity (TAC) of QCT and formulations A16 and A22 were determined using OxiSelect ${ }^{\text {TM }}$ TAC Assay Kit (Cell Biolabs, Inc., San Diego, CA, USA; Catalog Number: STA-360). Values are mean \pm SD $(n=3) . * * P<0.01$, $* * * P<0.00$ I versus quercetin treatment at the same dose; $P<0.01, \ldots P<0.00$ I versus A16 treatment at the same dose; A16, mixed polymeric micelles of PI23/ P407 (7:3 molar ratio) containing QCT; A22, mixed polymeric micelles of PI23/ P407/TPGS (7:2:I molar ratio) containing QCT.

Abbreviations: QCT, quercetin; CRE, copper reducing equivalent; TPGS, tocopheryl polyethylene glycol succinate.

preparation. These findings show the sustained release of QCT from the mixed micellar preparations and the release of QCT was significantly higher $(P<0.05)$ from A22 compared to A16 after different time intervals (up to $120 \mathrm{~h}$ ), except $48 \mathrm{~h}$. The faster release of QCT from A22 might be due to the presence of TPGS in the micelles. TPGS is known to increase the ratio of the hydrophilic portion in the mixed micelles and facilitates entry of water into the core of micelles and forms more hydrophilic channels. ${ }^{44}$ Drug diffusion and polymer erosion or swelling might be the possible mechanism of QCT release from the mixed micelles. ${ }^{58}$ The micellar preparations enhanced the solubility of QCT and sustained the release of QCT.

\section{Total antioxidant capacity}

TAC of pure QCT, A16, and A22 was determined using OxiSelect ${ }^{\mathrm{TM}} \mathrm{TAC}$ Assay Kit. The TACs of both polymeric

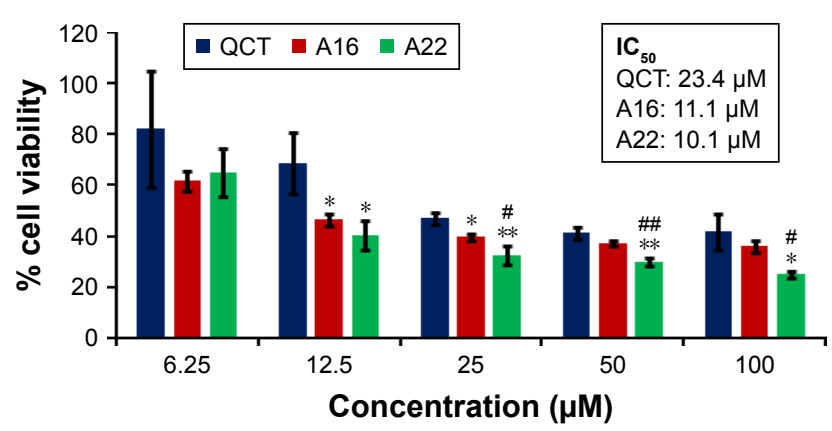

Figure 9 In vitro cytotoxicity of QCT, A16, and A22 in SKOV-3 cells after 72 h of incubation by MTT assay. Values are mean $\pm S D(n=3)$. $* P<0.05, * * P<0.01$ versus QCT treatment at the same dose; ${ }^{\# P}<0.05,{ }^{\# P}<0.01$ versus $A 16$ treatment the same dose; AI6, mixed polymeric micelles of PI23/P407 (7:3 molar ratio) containing QCT; A22, mixed polymeric micelles of PI23/P407/TPGS (7:2:1 molar ratio) containing QCT.

Abbreviations: $I C_{50}$, concentration which inhibited $50 \%$ growth; QCT, quercetin; TPGS, tocopheryl polyethylene glycol succinate.

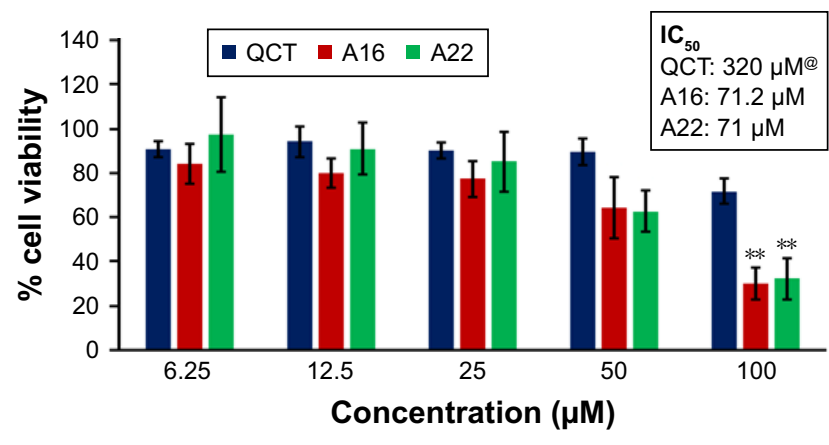

Figure 10 In vitro cytotoxicity of QCT, AI6, and A22 in NCI/ADR cells after $72 \mathrm{~h}$ of incubation by MTT assay. Values are mean $\pm S D(n=3)$. $* * P<0.0$ I versus QCT treatment at the same dose; A16, mixed polymeric micelles of PI23/P407 (7:3 molar ratio) containing QCT; A22, mixed polymeric micelles of PI23/P407/ TPGS (7:2:I molar ratio) containing QCT; @, QCT was also screened at higher doses to determine $I_{50}$ (data not shown in figure).

Abbreviations: $I C_{50}$, concentration which inhibited $50 \%$ growth; QCT, quercetin; TPGS, tocopheryl polyethylene glycol succinate.

mixed micelles (A16 and A22) were significantly higher compared to pure QCT (Figure 8). In addition, at higher concentrations, the TAC of A22 was significantly more compared to A16.

\section{In vitro cytotoxicity study}

In vitro cytotoxicity of empty micelles, free QCT, A16, and A22, treatment against MCF-7 and MDA-MB-231, SKOV-3, and NCI/ADR cell lines was assessed after $72 \mathrm{~h}$ of incubation by MTT assay. The MTT assay results in different cell lines treated with QCT and the drug formulations (A16 and A22) are represented in Figures 9-12, while that of the empty micelles are shown in Figures 13-16. The $\mathrm{IC}_{50}$ of pure QCT in MCF-7, MDA-MB-231, SKOV-3, and NCI/ADR cell lines was $167,157.2,23.4$, and $320 \mu \mathrm{M}$, respectively. The $\mathrm{IC}_{50}$ of A16 in MCF-7, MDA-MB-231, SKOV-3, and NCI/ADR cell

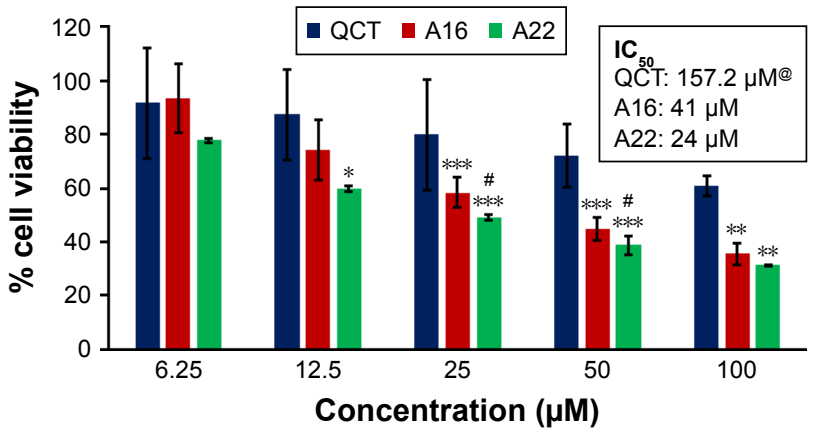

Figure II In vitro cytotoxicity of QCT, AI6, and A22 in MDA-MB-23I cells after $72 \mathrm{~h}$ of incubation by MTT assay. Values are mean $\pm S D(n=3)$. $* P<0.05, * * P<0.0$ I, *** $P<0.001$ versus $Q C T$ treatment at the same dose; ${ }^{\#} P<0.05$ versus $A 16$ treatment at the same dose; AI6, mixed polymeric micelles of PI23/P407 (7:3 molar ratio) containing QCT; A22, mixed polymeric micelles of PI23/P407/TPGS (7:2:1 molar ratio) containing QCT; @, QCT was also screened at higher doses to determine $\mathrm{IC}_{50}$ (data not shown in figure).

Abbreviations: $I C_{50}$, concentration which inhibited $50 \%$ growth; QCT, quercetin; TPGS, tocopheryl polyethylene glycol succinate. 


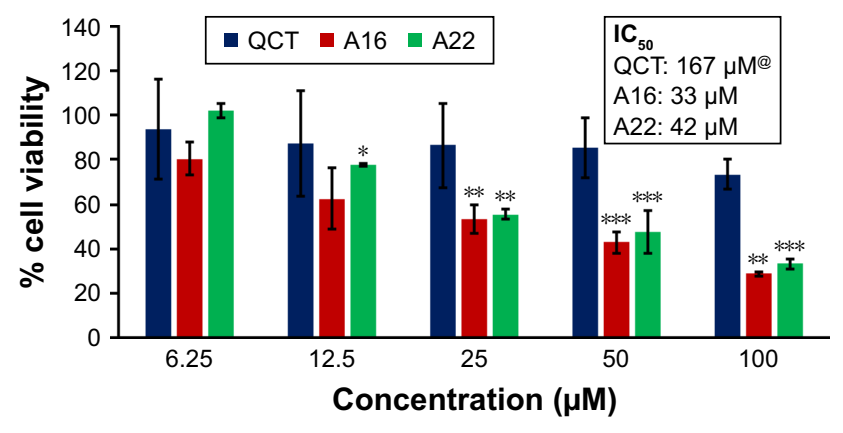

Figure 12 In vitro cytotoxicity of QCT, AI6, and A22 in MCF-7 cells after $72 \mathrm{~h}$ of incubation by MTT assay. Values are mean $\pm S D(n=3)$. $* P<0.05, * * P<0.01$, $* * * P<0.001$ versus $Q C T$ treatment at the same dose; A I6, mixed polymeric micelles of PI23/P407 (7:3 molar ratio) containing QCT; A22, mixed polymeric micelles of PI23/P407/TPGS (7:2:I molar ratio) containing QCT; @, QCT was also screened at higher doses to determine $\mathrm{IC}_{50}$ (data not shown in figure).

Abbreviations: $\mathrm{IC}_{50}$, concentration which inhibited $50 \%$ growth; QCT, quercetin; TPGS, tocopheryl polyethylene glycol succinate.

lines was $33,41,11.1$, and $71.2 \mu \mathrm{M}$, respectively, while that of A22 was found to be $42,24,10.1$, and $71 \mu \mathrm{M}$ respectively. Both the MPM formulations containing QCT exhibited enhanced cytotoxicity compared to pure QCT. Formulation A22 at higher doses significantly lowered the percentage cell viability of SKOV-3 and MDA-MB-231 cell lines compared to A16 (Figures 9 and 11). However, there was no significant difference in the cytotoxicity of A16 and A22 against other cell lines. Free QCT exhibited lower cytotoxicity which may be due to the efflux of QCT by the P-gp pumps. However, the mixed micelles were picked up by the cells via endocytosis and may not be susceptible for efflux by the P-gp pumps, allowing the QCT to remain inside the cells for a longer duration and resulting in higher cytotoxicity. Earlier literature also reported similar results. ${ }^{44,59}$ Further, the enhanced cytotoxicity of mixed micelles may be due to the presence of Pluronics and TPGS, which are known to be inhibitors of P-gp and reduce the efflux of drugs. ${ }^{60-62}$ TPGS also shows in vitro

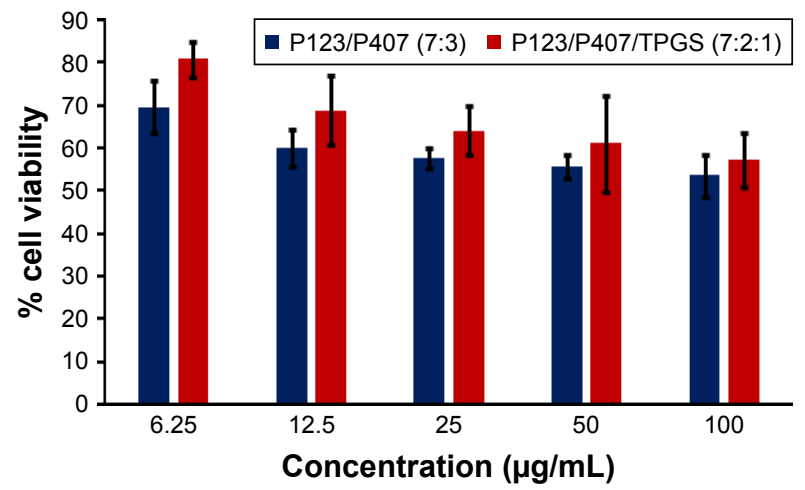

Figure 13 In vitro cytotoxicity of empty micelles in NCI/ADR cells after $72 \mathrm{~h}$ of incubation by MTT assay. Values are mean \pm SD $(n=3)$.

Abbreviation: TPGS, tocopheryl polyethylene glycol succinate.

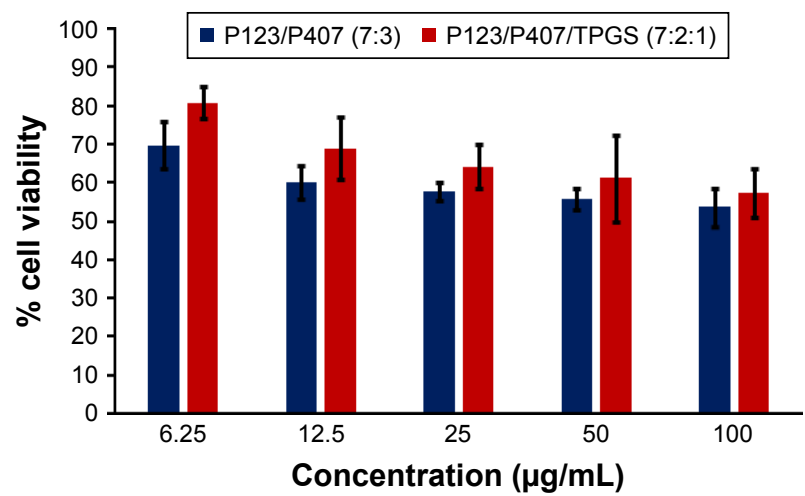

Figure 14 In vitro cytotoxicity of empty micelles in SKOV-3 cells after $72 \mathrm{~h}$ of incubation by MTT assay. Values are mean \pm SD $(n=3)$.

Abbreviation: TPGS, tocopheryl polyethylene glycol succinate.

and in vivo anticancer activity against various cancer cells due to its apoptosis-inducing properties. ${ }^{63-65} \mathrm{P} 123 / \mathrm{P} 407$ (7:3 molar ratio) and P123/P407/TPGS (7:2:1 molar ration) empty micelles displayed cytotoxicity in all four cell lines at higher concentrations, which may be due to the combined effect of Pluronics and TPGS. ${ }^{25,63}$ P123/P407/TPGS (7:2:1 molar ration) empty micelles exhibited significantly $(P<0.05)$ higher cytotoxicity against breast cancer cell lines compared to P123/P407 (7:3 molar ratio) empty micelles (Figures 15 and 16). Further, the higher cytotoxicity of the mixed micelles containing QCT may be the result of increased cellular uptake of QCT from the micelles than from the free drug. ${ }^{25,47} \mathrm{In}$ vitro cytotoxicity can be determined by several assays such as lactate dehydrogenase (LDH) leakage assay, neutral red assay, and protein assay in addition to MTT assay. In the current study, we used the MTT assay as it is one of the most sensitive assays in detecting cytotoxic events and is ranked better compared to the LDH leakage assay. ${ }^{66}$

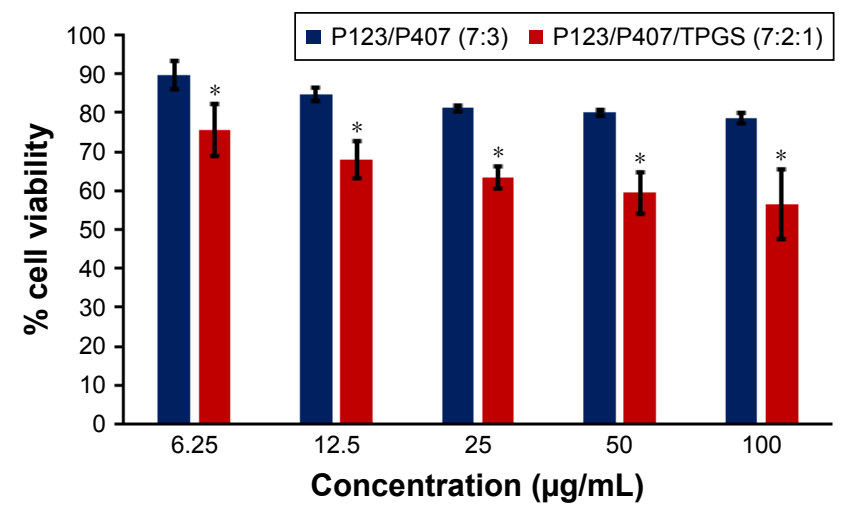

Figure 15 In vitro cytotoxicity of empty micelles in MCF-7 cells after $72 \mathrm{~h}$ of incubation by MTT assay. Values are mean \pm SD $(n=3) ; * P<0.05$ versus $P$ I23/P407 (7:3) treatment at the same dose.

Abbreviation: TPGS, tocopheryl polyethylene glycol succinate. 


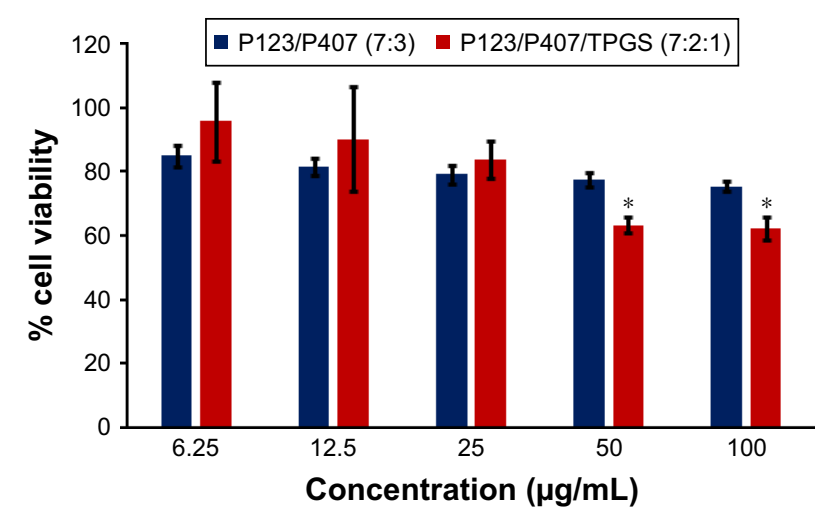

Figure 16 In vitro cytotoxicity of empty micelles in MDA-MB-23। cells after $72 \mathrm{~h}$ of incubation by MTT assay. Values are mean \pm SD $(n=3)$; $* P<0.05$ versus PI23/P407 (7:3) treatment at the same dose.

Abbreviation: TPGS, tocopheryl polyethylene glycol succinate.

\section{Conclusion}

MPMs containing QCT were formulated by thin-film hydration method. The mixed micelles prepared from P123 and P407 (7:3 molar ratio) or P123, P407, and TPGS (7:2:1 molar ratio) have smaller particle size, low CMC, negative zeta potential, and high drug EE. Low CMC suggests stability of the micelles upon dilution. The sustained release of QCT from the micelles demonstrates the encapsulation of QCT in the inner core. The selected micelles showed increased in vitro cytotoxicity in breast (MCF-7 and MDAMB-231), ovarian (SKOV-3), and multidrug resistant (NCI/ ADR) cancer cells compared to free QCT. The micelles also exhibited an enhanced antioxidant activity over the free QCT. In conclusion, the mixed micellar nanoformulations could be used for delivery of QCT for treatment of cancer. The in vivo evaluation of the preparations is warranted in the future.

\section{Acknowledgments}

This project was financially supported by King Saud University, Vice Deanship of Research Chairs, Kayyali Chair for Pharmaceutical Industries through the grant number KM-2017. Financial support of University Grants Commission, New Delhi, India, to Arjun Patra for Postdoctoral Research as Raman Fellow (F No 5-63/2016-IC) is greatly acknowledged. A part of the manuscript has been presented during the 38th Annual Central California Research Symposium at California State University, Fresno, USA.

\section{Disclosure}

The authors report no conflicts of interest in this work.

\section{References}

1. Scalbert A, Williamson G. Dietary intake and bioavailability of polyphenols. J Nutr. 2000;130:2073-2085.

2. Saito K. Possible site of flavonoid synthesis in the photosynthetic apparatus. Biochem J. 1974;144:431-432.

3. Kumar VD, Verma PRP, Singh SK. Development and evaluation of biodegradable polymeric nanoparticle for the effective delivery of quercetin using quality by design approach. LWT - Food Sci Technol. 2015; 61:330-338.

4. Bischoff SC. Quercetin: potentials in the prevention and therapy of disease. Curr Opin Clin Nutr Metab Care. 2008;11:733-740.

5. Maria H, Concepcion SM, Sonia PT. Flavonoid-flavonoid interaction and its effect on their antioxidant activity. Food Chem. 2010;121: 691-696.

6. Fang XK, Gao J, Zhu DN. Kaempferol and quercetin isolated from Euonymus alatus improve glucose uptake of 3T3-L1 cells without adipogenesis activity. Life Sci. 2008;82:615-622.

7. Boots AW, Haenen GR, Bast A. Health effects of quercetin: from antioxidant to nutraceutical. Eur J Pharmacol. 2008;585:325-337.

8. Rogerio AP, Dora CL, Andrade EL, et al. Anti-inflammatory effect of quercetin-loaded microemulsion in the airways allergic inflammatory model in mice. Pharmacol Res. 2010;61:288-297.

9. Hirpara KV, Aggarwal P, Mukherjee AJ, Joshi N, Burman AC. Quercetin and its derivatives: synthesis, pharmacological uses with special emphasis on anti-tumor properties and prodrug with enhanced bioavailability. Anticancer Agents Med Chem. 2009;9:138-161.

10. Huang SL, Hsu CL, Yen GC. Growth inhibitory effect of quercetin on SW 872 human liposarcoma cells. Life Sci. 2006;79:203-209.

11. Vijayababu MR, Arunkumar A, Kanagaraj P, Venkatraman P, Krishnamoorthy G, Arunakaran J. Quercetin downregulates matrix metalloproteinases 2 and 9 proteins expression in prostate cancer cells (PC-3). Mol Cell Biochem. 2006;287:109-116.

12. Men K, Duan X, Wei XW, et al. Nanoparticle-delivered quercetin for cancer therapy. Anticancer Agents Med Chem. 2014;14:826-832.

13. Ribeiro ME, Vieira IG, Cavalcante IM, et al. Solubilization of griseofulvin, quercetin and rutin in micellar formulations of triblock copolymers E62P39E62 and E137S18E137. Int J Pharm. 2009;378: 211-214.

14. Gupta K, Panda D. Perturbation of microtubule polymerization by quercetin through tubulin binding: a novel mechanism of its antiproliferative activity. Biochemistry. 2002;41:13029-13038.

15. Jung YH, Heo J, Lee YJ, Kwon TK, Kim YH. Quercetin enhances TRAIL induced apoptosis in prostate cancer cells via increased protein stability of death receptor 5. Life Sci. 2010;86:351-357.

16. Gulati N, Laudet B, Zohrabian VM, Murali R, JhanwarUniyal M. The antiproliferative effect of quercetin in cancer cells is mediated via inhibition of the P13K-Akt/PKB pathway. Anticancer Res. 2006; 26:1177-1181.

17. Zhao L, Shi Y, Zou S, Sun M, Li L, Zhai G. Formulation and in vitro evaluation of quercetin loaded polymeric micelles composed of Pluronic P123 and D- $\alpha$-tocopheryl polyethylene glycol succinate. J Biomed Nanotechnol. 2011;7:358-365.

18. Gao Y, Wang Y, Ma Y, et al. Formulation optimization and in situ absorption in rat intestinal tract of quercetin-loaded microemulsion. Colloids Surf B. 2009;71:306-314.

19. Gugler R, Leschik M, Dengler HJ. Disposition of quercetin in man after single oral and intravenous doses. Eur J Clin Pharmacol. 1975;9: 229-234.

20. Ferry DR, Smith A, Malkhandi J, et al. Phase I clinical trial of the flavonoid quercetin: pharmacokinetics and evidence for in vivo tyrosine kinase inhibition. Clin Cancer Res. 1996;2:659-668.

21. Yuan ZP, Chen LJ, Fan LY, et al. Liposomal quercetin efficiently suppresses growth of solid tumors in murine models. Clin Cancer Res. 2006;12:3193-3199. 
22. Gong J, Chen M, Zheng Y, Wang S, Wang Y. Polymeric micelles drug delivery system in oncology. J Control Release. 2012;159:312-323.

23. Lu Y, Park K. Polymeric micelles and alternative nanonized delivery vehicles for poorly soluble drugs. Int J Pharm. 2013;453:198-214.

24. Maeda H, Wu J, Sawa T, Matsumura Y, Hori K. Tumor vascular permeability and the EPR effect in macromolecular therapeutics: a review. J Control Release. 2000;65:271-284.

25. Chen LC, Chen YC, Su CY, Hong CS, Ho HO, Sheu MT. Development and characterization a of self-assembling lecithin-based mixed polymeric micelles containing quercetin in cancer treatment and an in vivo pharmacokinetic study. Int J Nanomed. 2016;11:1557-1566.

26. Guan X, Gao M, Xu H, et al. Quercetin-loaded poly (lactic-coglycolic acid)-D-a-tocopheryl polyethylene glycol 1000 succinate nanoparticles for the targeted treatment of liver cancer. Drug Deliv. 2016;23:3307-3318.

27. Pimple S, Manjappa AS, Ukawala M, Murthy R. PLGA nanoparticles loaded with etoposide and quercetin dehydrate individually: in vitro cell line study to ensure advantage of combination therapy. Cancer Nanotechnol. 2012;3:25-36.

28. Gao L, Liu G, Wang X, Liu F, Xu Y, Ma J. Preparation of a chemically stable quercetin formulation using nanosuspension technology. Int $J$ Pharm. 2011;404:231-237.

29. Mandal AK, Das S, Mitra S, Chakrabarti RN, Chatterjee M, Das N. Vesicular flavonoid in combating diethylnitrosamine induced hepatocarcinoma in rat model. $J$ Exp Ther Oncol. 2008;7:123-133.

30. Pouci F, Morelli C, Cirillo G, et al. Anticancer activity of quercetin-based polymer towards HeLa cancer cells. Anticancer Res. 2012;32:2843-2847.

31. Kale R, Saraf M, Juvekar A, Tayade P. Decreased B16F10 melanoma growth and impaired tumor vascularization in BDF1 mice with quercetin-cyclodextrin binary system. $J$ Pharm Pharmacol. 2006;58: 1351-1358.

32. Torchilin V. Tumor delivery of macromolecular drugs based on the EPR effect. Adv Drug Deliv Rev. 2011;63:131-135.

33. Mikhail AS, Allen C. Block copolymer micelles for delivery of cancer therapy: transport at the whole body, tissue and cellular levels. J Control Release. 2009;138:214-223.

34. Wakaskar RR, Bathena SPR, Tallapaka S, et al. Peripherally crosslinking the shell of core-shell polymer micelles decreases premature release of physically loaded combretastatin A4 in whole blood and increases its mean residence time and subsequent potency against primary murine breast tumors after IV administration. Pharm Res. 2015;32: $1028-1044$.

35. Vaishya RD, Gokulgandhi M, Patel S, Minocha M, Mitra AK. Novel dexamethasone-loaded nanomicelles for the intermediate and posterior segment uveitis. AAPS PharmSciTech. 2014;15:1238-1251.

36. Nirei $\mathrm{T}$, Ishihara $\mathrm{S}$, Tanaka $\mathrm{T}$, et al. Polymeric micelles loaded with (1,2-diaminocyclohexane)platinum(II) against colorectal cancer. J Surg Res. 2017;218:334-340.

37. Ma H, Jiang C. DHA and pGPMA dual modified $\mathrm{pH}$ sensitive polymeric micelles for target treatment of liver cancer, J Pharm Sci. 2018; 107:595-603.

38. Wen R, Banik B, Pathak RK, Kumar A, Kolishetti N, Dhar S. Nanotechnology inspired tools for mitochondrial dysfunction related diseases. Adv Drug Deliv Rev. 2016;99:52-69.

39. Chen H, Ruckenstein E. Formation and degradation of multicomponent multicore micelles: insights from dissipative particle dynamics simulations. Langmuir. 2013;29:5428-5434.

40. Chen H, Ruckenstein E. Micellar structures in nanoparticle-multiblock copolymer complexes. Langmuir. 2014;30:3723-3728.

41. Wen R, Dhar S. Turn up the cellular power generator with vitamin E analogue formulation. Chem Sci. 2016;7:5559-5567.

42. Chen H, Ruckenstein E. Self-assembly of $\pi$-shaped copolymers. Soft Matter. 2012;8:1327-1333.

43. Chen H, Ruckenstein E. Formation of complex colloidal particles: morphologies and mechanisms. Soft Matter. 2012;8:8911-8916.
44. Wei Z, Hao J, Yuan S, et al. Paclitaxel-loaded Pluronic P123/F127 mixed polymeric micelles: formulation, optimization and in vitro characterization. Int J Pharm. 2009;376:176-185.

45. Kabanov AV, Batrakova EV, Alakhov VY. Pluronic block copolymers as novel polymer therapeutics for drug and gene delivery. $J$ Control Release. 2002;82:189-212.

46. Saxena V, Hussain MD. Polymeric mixed micelles for delivery of curcumin to multidrug resistant ovarian cancer. J Biomed Nanotechnol. 2013;9:1146-1154.

47. Saxena V, Hussain MD. Poloxamer 407/TPGS mixed micelles for delivery of gambogic acid to breast and multidrug-resistant cancer. Int J Nanomed. 2012;7:713-721.

48. Harisa GI, Attia SM, Zoheir KMA, Alanazi FK. Chitosan treatment abrogates hypercholesterolemia-induced erythrocyte's arginase activation. Saudi Pharm J. 2017;25:120-127.

49. Batrakova EV, Kabanov AV. Pluronic block copolymers: evolution of drug delivery concept from inert nanocarriers to biological response modifiers. J Control Release. 2008;130:98-106.

50. Oh KT, Bronich TK, Kabanov AV. Micellar formulations for drug delivery based on mixtures of hydrophobic and hydrophilic Pluronic block copolymers. J Control Release. 2004;94:411-422.

51. Zhang W, Shi Y, Chen Y, Ye J, Sha X, Fang X. Multifunctional Pluronic P123/F127 mixed polymeric micelles loaded with paclitaxel for the treatment of multidrug resistant tumors. Biomaterials. 2011;32:2894-2906.

52. Wu SH-W, Hopkins WK. Characteristics of D- $\alpha$-tocopheryl PEG1000 succinate for applications as an absorption enhancer in drug delivery systems. Pharm Tech. 1999;23:52-68.

53. Mi Y, Liu Y, Feng SS. Formulation of docetaxel by folic acidconjugated D-alpha-tocopheryl polyethylene glycol succinate 2000 (Vitamin E TPGS(2k)) micelles for targeted and synergistic chemotherapy. Biomaterials. 2011;32:4058-4066.

54. Liu W, Guo R. Interaction between flavonoids, quercetin and surface aggregates with different charges. J colloid Interface Sci. 2006;302: 625-632.

55. Sadoqi M, Lau-Cam CA, Wu SH. Investigation of the micellar properties of the tocopheryl polyethylene glycolsuccinate surfactants TPGS 400 and TPGS 1000 by steady state fluorometry. J Colloid Interface Sci. 2009;333:585-589.

56. Sezgin Z, Yuksel N, Baykara T. Preparation and characterization of polymeric micelles for solubilization of poorly soluble anticancer drugs. Eur J Pharm Biopharm. 2006;64:261-268.

57. Yang X, Li L, Wang Y, Tan Y. Preparation, pharmacokinetics and tissue distribution of micelles made of reverse thermo-responsive polymers. Int J Pharm. 2009;370:210-215.

58. Kim KS, Park SJ. Effect of porous silica on sustained release behaviors of $\mathrm{pH}$ sensitive pluronic F127/poly(acrylic acid) hydrogels containing tulobuterol. Colloids Surf B Biointerfaces. 2010;80:240-246.

59. Gabizon AA. Selective tumor localization and improved therapeutic index of anthracyclines encapsulated in long-circulating liposomes. Cancer Res. 1992;52:891-896.

60. Guan Y, Huang J, Zuo L, et al. Effect of pluronic P123 and F127 block copolymer on P-glycoprotein transport and CYP3 A metabolism. Arch Pharm Res. 2011;34:1719-1728.

61. Collnot EM, Baldes C, Wempe MF, et al. Mechanism of inhibition of P-glycoprotein mediated efflux by vitamin E TPGS: influence on ATPase activity and membrane fluidity. Mol Pharm. 2007;4:465-474.

62. Varma MV, Panchagnula R. Enhanced oral paclitaxel absorption with vitamin E-TPGS: effect on solubility and permeability in vitro, in situ and in vivo. Eur J Pharm Sci. 2005;25:445-453.

63. Neophytou CM, Constantinou C, Papageorgis P, Constantinou AI. D-alphatocopheryl polyethylene glycol succinate (TPGS) induces cell cycle arrest and apoptosis selectively in Survivin-overexpressing breast cancer cells. Biochem Pharmacol. 2014;89:31-42.

64. Zhao H, Yung LY. Addition of TPGS to folate-conjugated polymer micelles for selective tumor targeting. J Biomed Mater Res A. 2009;91:505-518. 
65. Cagel M, Tesan FC, Bernabeu E, et al. Polymeric mixed micelles as nanomedicines: achievements and perspectives. Eur $J$ Pharm Biopharm. 2017;113:211-228.
66. Fotakis G, Timbrell JA. In vitro cytotoxicity assays: comparison of LDH, neutral red, MTT and protein assay in hepatoma cell lines following exposure to cadmium chloride. Toxicol Lett. 2006;160:171-177.
International Journal of Nanomedicine

\section{Publish your work in this journal}

The International Journal of Nanomedicine is an international, peerreviewed journal focusing on the application of nanotechnology in diagnostics, therapeutics, and drug delivery systems throughou the biomedical field. This journal is indexed on PubMed Central, MedLine, CAS, SciSearch $\AA$, Current Contents ${ }^{\circledR} /$ Clinical Medicine,

\section{Dovepress}

Journal Citation Reports/Science Edition, EMBase, Scopus and the Elsevier Bibliographic databases. The manuscript management system is completely online and includes a very quick and fair peer-review system, which is all easy to use. Visit http://www.dovepress.com/ testimonials.php to read real quotes from published authors.

Submit your manuscript here: http://www.dovepress.com/international-journal-of-nanomedicine-journal 